American J. of Engineering and Applied Sciences 2 (2): 438-445, 2009

ISSN 1941-7020

(C) 2009 Science Publications

\title{
Degradation of High Voltage Polymeric Insulators in Arid Desert's Simulated Environmental Conditions
}

\author{
Yasin Khan \\ Department of Electrical Engineering, College of Engineering, \\ King Saud University, Kingdom of Saudi Arabia
}

\begin{abstract}
Problem statement: High Voltage (HV) polymeric insulators are replacing ceramic insulator commonly used for HV outdoor networks due to their ease of handling, reliability and cost. However, their long term performance and reliability are major concerns to power utilities. Approach: To investigate their performance in arid desert's conditions, two types of HV composite insulators were aged as per International Electrochemical Commission (IEC) standard-61109. Additional test samples were subjected to accelerated aging conditions simulating the actual Ultraviolet (UV) radiation intensity and temperature in the inland desert. Results: This study described the experimental results of the effects of thermo electric stress and UV radiations on the polymeric insulators aged under two conditions i.e., as per IEC standard and modified IEC standard that simulates the inland arid desert. The tests results after the artificial accelerated aging indicated that the dielectric response of thermoplastic insulators under the tested thermo-electric cum UV-irradiations outperforms Silicone rubber insulators. Conclusion: From the obtained results it will be easy to assess the performance and suitability of composite insulators for their applications in arid desert environments.
\end{abstract}

Key words: High voltage, polymeric insulator, accelerated aging, UV radiations, silicon rubber, thermoplastic elastomer, flashover voltage, lightning impulse

\section{INTRODUCTION}

The use of polymeric insulators for outdoor transmission lines has rapidly increased during the last two decades. Both service experience ${ }^{[1]}$ and the laboratory tests demonstrated a better performance in contaminated conditions ${ }^{[2,3]}$.

Porcelain and glass have traditionally been used as the oldest and most economic insulating materials and their advantages and drawbacks are well known. However, the polymeric insulators have replaced ceramic units due to wide range of reasons such as lightweight, less cost, high mechanical strength, resistance to contamination ${ }^{[1-3]}$. Figure 1 shows the breakup of these reasons obtained during a survey ${ }^{[4]}$. During the last three decades huge data is collected about the worldwide use and utility service experience of polymeric insulators by different manufacturers/research institutes such as $\mathrm{EPRI}^{[4]}$, CIGRE $^{[5]}$ and CRIEPI (Japan). Figure 2 shows the results of a survey done by CIGRE to investigate the global distribution of composite insulators at voltage levels above $69 \mathrm{kV}$, indicated that GCC is one of the regions where composite insulators are gaining ground $^{[5,6]}$.

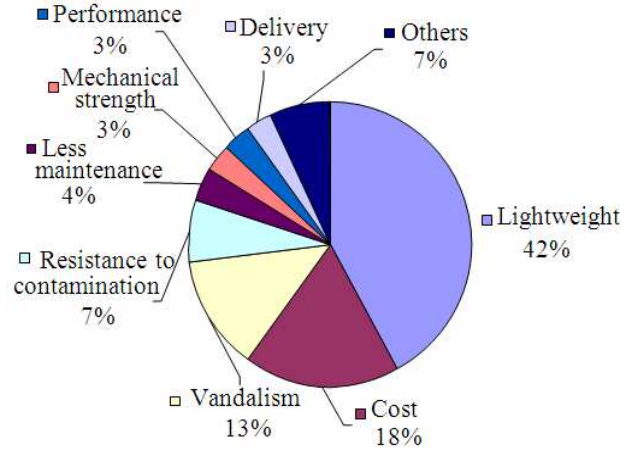

Fig. 1: Reasons for applying polymeric insulators ${ }^{[4]}$

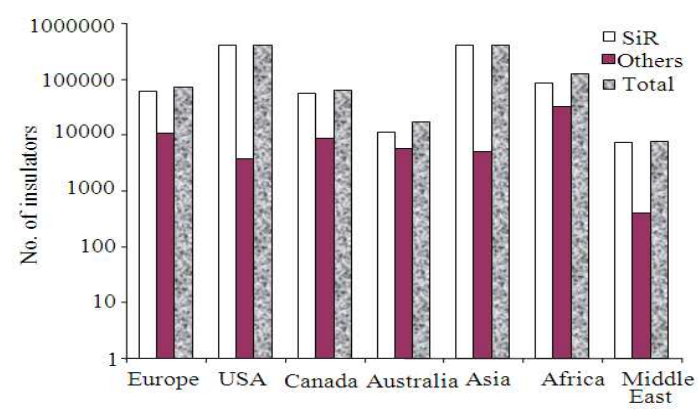

Fig. 2: Composite insulators used in the world 
Polymeric materials are badly affected by environmental stresses like UV-radiations, heat, contaminations and moisture ${ }^{[2,7,9]}$. The weather conditions in the Middle East including Saudi Arabia are significantly harsh and changing from the daytime to the night. The inland areas of Saudi Arabia are very hot, dry and dusty.

The UV radiation level is extremely high in this region $^{[11]}$. The high degree of UV radiation can cause physical as well as chemical changes. The above factors are not systematically considered by any researcher. This study discuss the degree of degradation of the tested composite insulators artificially aged in accelerated aging conditions under two scenarios i.e., as per IEC standard and modified IEC standard that simulates the inland arid desert. From the obtained results it is easy to assess the performance and suitability of composite insulators for their applications in arid desert environments.

\section{MATERIALS AND METHODS}

According to IEC Std. $61109^{[8]}$ for the accelerated aging process of polymeric insulators, various stresses such as solar radiation (UV-A) intensity $\left(10 \mathrm{~W} \mathrm{~m}^{-2}\right)$, dry heat $\left(\sim 50^{\circ} \mathrm{C}\right)$, salt fog and artificial rain to be applied in a cyclic manner.

The meteorology of the inland arid desert situated in the central region of Saudi Arabia are very hot, dusty and with long dry spells in summer months with no or very little precipitation. In winter months, there is sparse occasional rain or no rain at all for years. Keeping in view these environmental conditions of the central region of Saudi Arabia, the rain and salt fog/clean fog parameters are not taken into consideration while performing the accelerated aging. Furthermore, as shown in Fig. 3, the actual level of UV-A radiations and temperature variations in central region of Saudi Arabia is quite higher as compared to the values recommended in the IEC std. $61109^{[8]}$.

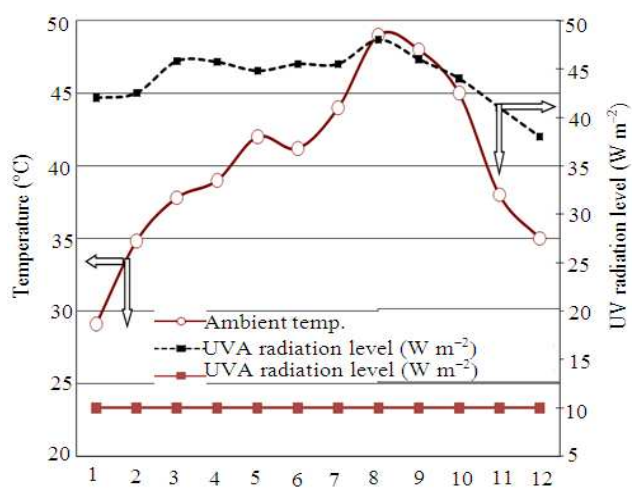

Fig. 3: Ave. monthly temperature (ambient) variation and actual UV-A radiation levels in central region Saudi Arabia
To simulate the ambient conditions of arid desert, a wooden chamber of approximately 120 (wide) $\times 120$ (high) $\times 180 \mathrm{~cm}$ (long) dimensions was fabricated for the accelerated aging process for the Silicone Rubber (SiR) and Thermoplastic Elastomer (TPE) polymeric insulators. A schematic diagram of the chamber with suspension insulators in place and other accessories is shown in Fig. 4. Based on the above discussion, two types of experimental conditions were created in the accelerated aging test chamber for each type of tested insulator by applying different stresses mentioned in Table 1, i.e.:

- $\quad$ Case 1: Based on the IEC std. 61109

- Case 2: Modified aging cycle based on the actual $\mathrm{UV}-\mathrm{A}$ radiations level $\left(40 \mathrm{~W} \mathrm{\textrm {m } ^ { - 2 }}\right)$ as shown in Fig. 4

In order to simulate solar irradiations, eight UV lamps (Fig. 4) having the same law, end cutoff wavelength as sunlight were utilized. The UV-A spectrum $(320 \sim 400 \mathrm{~nm})$ produced by these lamps as compared with that of sunlight, is shown in Fig. 5. The UV-A radiation intensity for the two cases was controlled by adjusting the distance between the lamps and insulators.

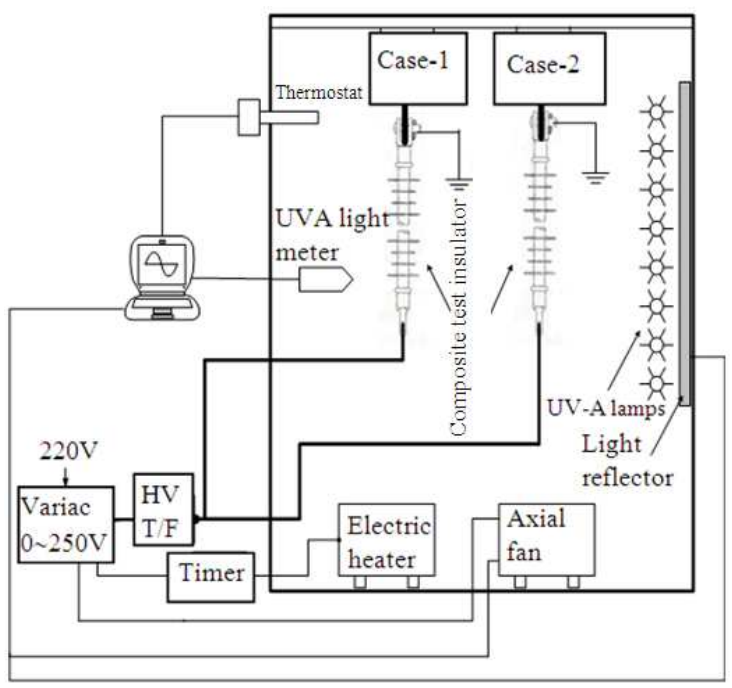

Fig. 4: Schematic diagram of accelerated aging cycle chamber

\begin{tabular}{llll}
\multicolumn{2}{l}{ Table } & 1: Applied stresses & \\
\hline No. & Stress type & Case 1 & Case 2 \\
\hline 1 & Voltage (p.u) & 1 & 1 \\
2 & Temperature $\left({ }^{\circ} \mathrm{C}\right)$ & $\sim 50$ & $\sim 50$ \\
3 & UV-radiation $\left(\mathrm{W} \mathrm{m}^{-2}\right)$ & 10 & 40 \\
\hline
\end{tabular}


Tested insulators: Three samples of each SiR and TPE suspension/dead end type insulators of $28 \mathrm{kV}_{\mathrm{L}-\mathrm{L}}$, procured from Canada and UK respectively were used for accelerated aging. Figure 6 shows the photographs of tested insulators. The salient dimensions of tested insulators are shown in Table 2.

Heating arrangements: A $2000 \mathrm{~W}$ tubular heater is used to develop heat. A PC based ON-OFF control system is used to maintain a relatively stable temperature in the chamber. The heat generated by the heater is uniformly distributed by an axial blower installed inside the chamber.

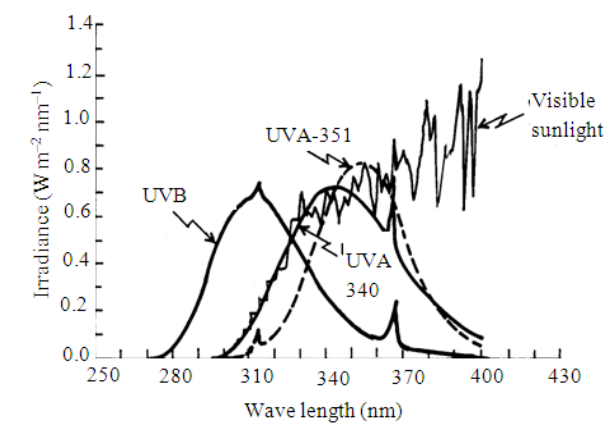

Fig. 5: Spectrum comparison of sunlight and UV radiations

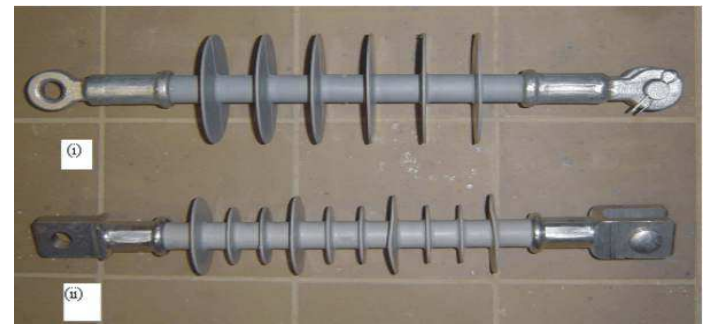

Fig. 6: Dead end/suspension polymeric insulator (i) TPE (ii) SiR

Table 2: Tested insulators details

\begin{tabular}{llrr}
\hline Specifications & Unit & \multicolumn{1}{c}{$\mathrm{SiR}$} & $\mathrm{TPE}$ \\
\hline Voltage class & $\mathrm{kV}$ & 28.00 & 28 \\
Section Length "L" & $\mathrm{mm}$ & 433.00 & 438 \\
Dry arcing Distance & $\mathrm{mm}$ & 290.00 & 285 \\
Leakage Distance & $\mathrm{mm}$ & 590.00 & 675 \\
Field strength mm kV & 21.09 & 24.10 & \\
Power frequency flashover: & & & \\
Dry & $\mathrm{kV}$ & 135.00 & 130 \\
Wet & $\mathrm{kV}$ & 105.00 & 114 \\
Impulse flashover & $\mathrm{kV}$ & 225.00 & 211 \\
\hline
\end{tabular}

Table 3: Accelerated aging cycle

\begin{tabular}{lllll}
\hline Time $(\mathrm{h})$ & $2 \sim 8 \mathrm{AM}$ & $8 \mathrm{AM} \sim 2$ PM & $2 \sim 8$ PM & 8 PM $\sim 2 \mathrm{AM}$ \\
\hline Voltage $(1 \mathrm{p.u})$ & On & On & On & On \\
Heating $\left(\sim 50^{\circ} \mathrm{C}\right)$ & On & Off & On & Off \\
UV-A radiations & On & Off & On & Off \\
\hline
\end{tabular}

The stresses mentioned in Table 1 above are applied in cyclic manner for duration of $1000 \mathrm{~h}$ is shown in Table 3. Each cycle lasts for $24 \mathrm{~h}$ and a programmed change takes place every $6 \mathrm{~h}$.

\section{RESULTS}

After performing the accelerated aging tests of the tested insulators as per case 1 and 2 mentioned above, various electrical, Scanning Electron Microscopy (SEM) based optical and X-Ray Photoelectron Spectroscopic (XPS) Analysis as well as visual tests were performed and the results are summarized below:

Impulse test: In order to investigate the effect of accelerated aging, all the aged as well as a virgin sample of each tested sample were subjected to standard impulse test under a standard lightning impulse wave of $(1.2 / 50 \mu \mathrm{s})$ with both polarities. The results reported here were corrected to the standard atmospheric conditions as per IEC Std. 60-1 ${ }^{[10]}$. Figure $7 \mathrm{a}$ and $\mathrm{b}$ shows the comparisons of the flashover voltages $\left(\mathrm{kV}_{\mathrm{p}}\right)$ for all the aged as well as new insulators for both polarities.

It is clear from Fig. 7 that $\mathrm{SiR}$ insulator comparatively better performs than TPE insulator as the effect of aging on SiR is slightly less as compared to TPE. For TPE insulator about 7 and $11.5 \%$ reduction as compared to virgin insulator has been observed under +LI and -LI, respectively. Whereas only about 7 9\% reduction is observed in case of type $\mathrm{SiR}$ insulators.

Power-frequency test: Dry and wet power frequency tests were also performed using $200 \mathrm{kV}$ power transformer. For wet tests, artificial rain was adjusted as per IEC-383 requirement for the resistivity and rain intensity ${ }^{[14]}$. The water resistivity was adjusted to $105 \Omega-\mathrm{m}$ and the intensity of rainfall was kept $1 \sim 1.5 \mathrm{~mm} \mathrm{~min}{ }^{-1}$ respectively. The flashover voltage values $\left(\mathrm{kV}_{\mathrm{rms}}\right)$, after correction to standard conditions, are shown in Fig. 8. Figure 8 shows that around 9\% reduction in flashover voltages in case of SiR for dry and wet conditions, respectively, whereas, 7 13\% reduction in flashover voltage was observed for the other aged insulators. All the results discussed above are summarized in Table 4.

\begin{tabular}{|c|c|c|c|c|c|}
\hline \multirow[b]{3}{*}{ Test type } & & \multicolumn{4}{|c|}{ Percentage of $\mathrm{V}_{\mathrm{BD}}$ reduction w.r.t. new insulator } \\
\hline & & \multicolumn{2}{|l|}{$\mathrm{SiR}$} & \multicolumn{2}{|l|}{ TPE } \\
\hline & & $\begin{array}{l}1 \mathrm{~mW} \mathrm{~cm}^{-2} \\
(\%)\end{array}$ & $\begin{array}{l}4 \mathrm{~mW} \mathrm{~cm}^{-2} \\
(\%)\end{array}$ & $\begin{array}{l}1 \mathrm{~mW} \mathrm{~cm}^{-2} \\
(\%)\end{array}$ & $\begin{array}{l}4 \mathrm{~mW} \mathrm{~cm}^{-2} \\
(\%)\end{array}$ \\
\hline Lightning & Positive & 9.0 & 10.0 & 4 & 11.0 \\
\hline impulse & Negative & 14.0 & 14.0 & 4 & 7.5 \\
\hline Power & Dry & 6.5 & 13.8 & Negligible & 4.7 \\
\hline frequency & Wet & 7.0 & 13.0 & Negligible & 4.5 \\
\hline
\end{tabular}


Am. J. Engg. \& Applied Sci., 2 (2):438-445, 2009

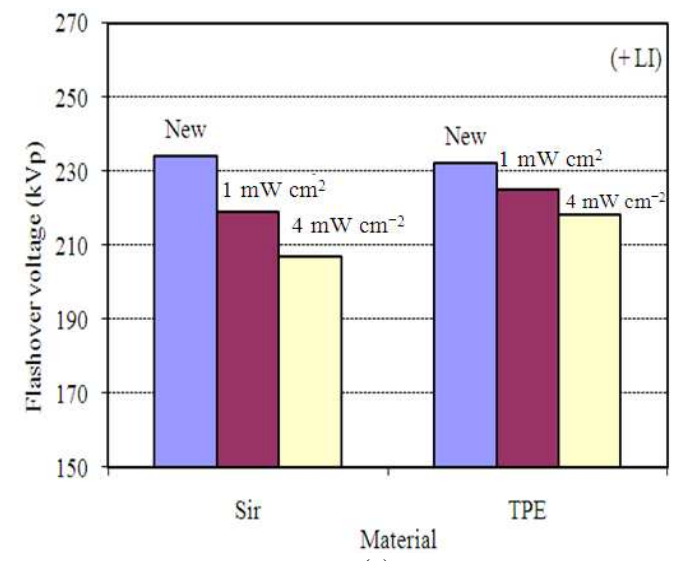

(a)

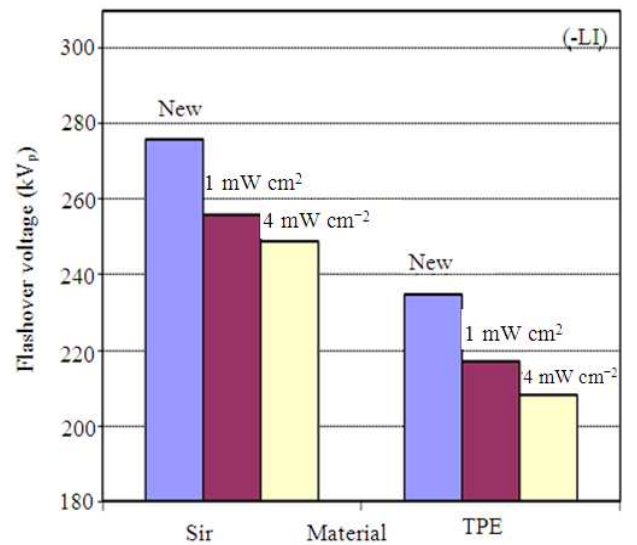

(b)

Fig. 7: Flashover voltages under lightning impulse. (a): Positive LI; (b): Negative LI

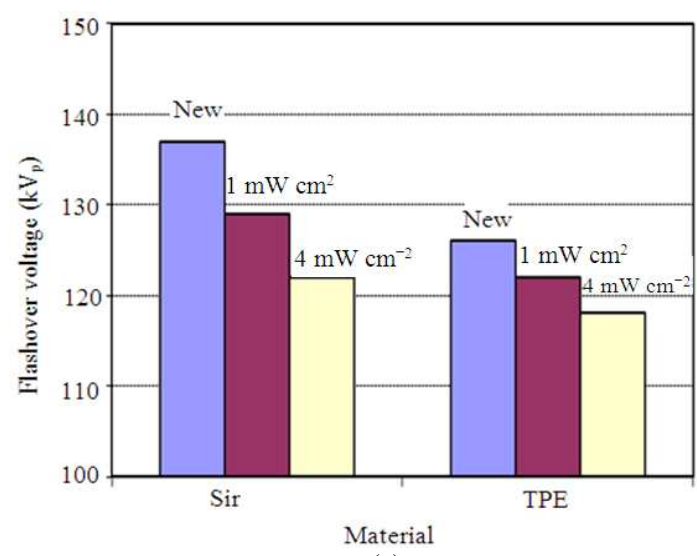

(a)

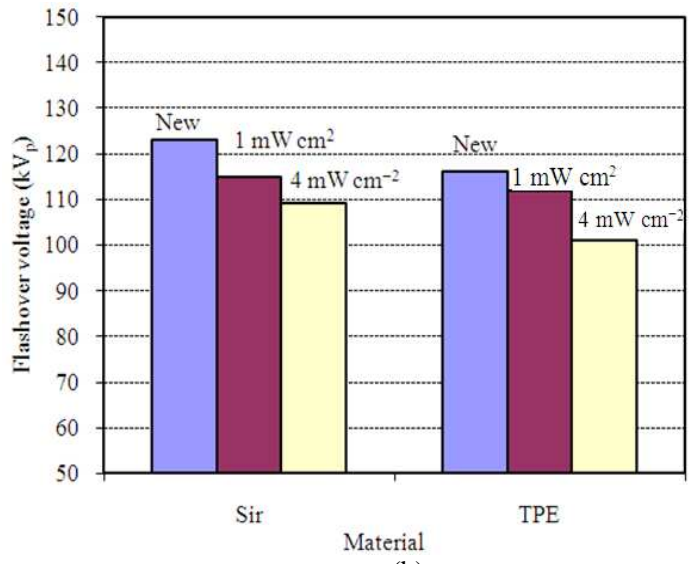

(b)

Fig. 8: Flashover voltage under $60 \mathrm{~Hz}$ AC voltage. (a): $60 \mathrm{~Hz}$ AC (Dry); (b): $60 \mathrm{~Hz} \mathrm{AC} \mathrm{(Wet)}$

Scanning Electron Microscopy (SEM): SEM is used to provide information about the surface topography of tested surfaces. Small samples $(3 \times 3 \mathrm{~mm})$ were sectioned from HV end of each insulator and their surface analysis was obtained using JEOL JSM-6360-A (Japan). Secondary Electron Imaging (SEI) was performed to study the surface morphology at an accelerating voltage of $20 \mathrm{kV}$. SEM photographs were captured for analyzing surface condition for all tested insulators at a magnification of $\times 500,1000,2000$ times.

Figure 9 shows SEM results of new as well as samples aged under UV radiation intensity 1 and $4 \mathrm{~mW} \mathrm{~cm}{ }^{-2}$. The virgin samples have a smooth, more homogenous and less porous surface while for aged insulators the surface roughness and porosity has increased with very visible cracks aging as shown in Fig. 9. Moreover, it may be pointed out that surface roughness on $\mathrm{SiR}$ is more as compared to TPE when

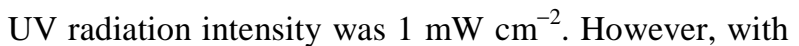
the increase in UV-intensity to $4 \mathrm{~mW} \mathrm{~cm}{ }^{-2}$, very visible surface degradation such as cracking in both types of materials is observed, as shown in Fig. 9c and f. This surface roughness has resulted due to localized degradation in both tested materials.

\section{X-Ray Photoelectron Spectroscopic (XPS) analysis:} XPS is a surface sensitive technique that probes the composition of the outer $10 \mathrm{~nm}$ of the surface. This method is used to obtain qualitative as well as quantitative information on the surface composition of samples. The sample XPS spectrum recorded for each tested specimen of $\mathrm{SiR}$ insulator is as shown in Fig. 10. These spectrums identify all the major elements such as oxygen, carbon, silicon and aluminum, in the investigated samples. 


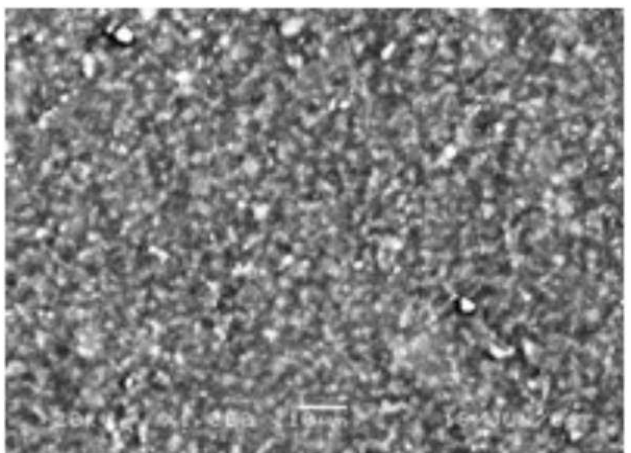

(a)

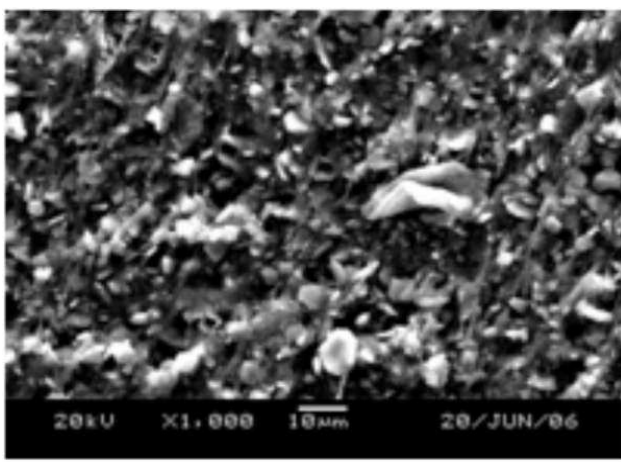

(c)

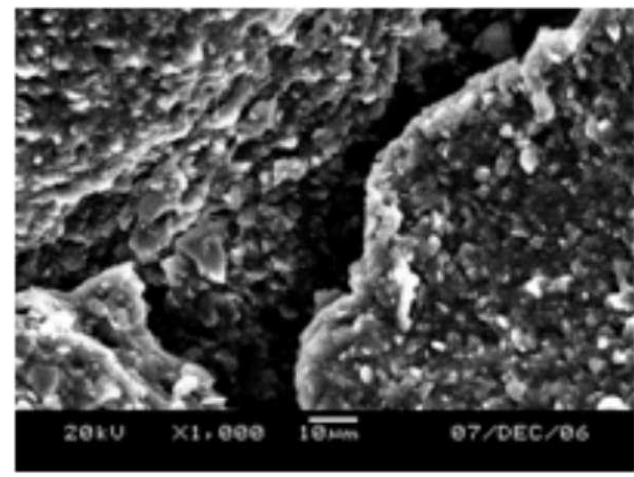

(e)

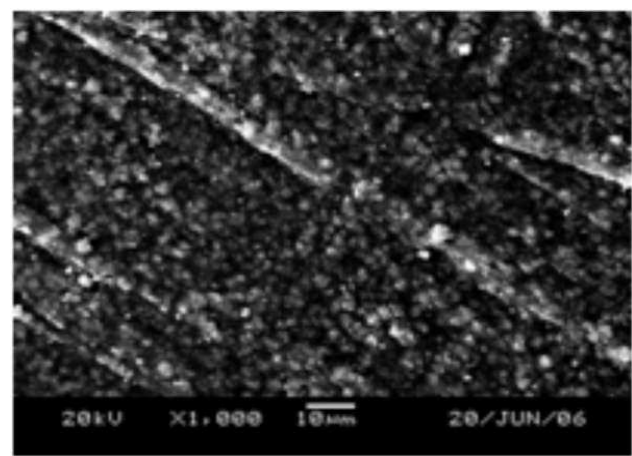

(b)

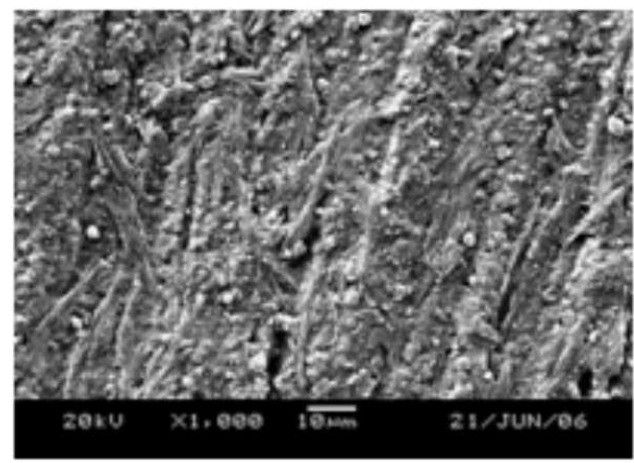

(d)

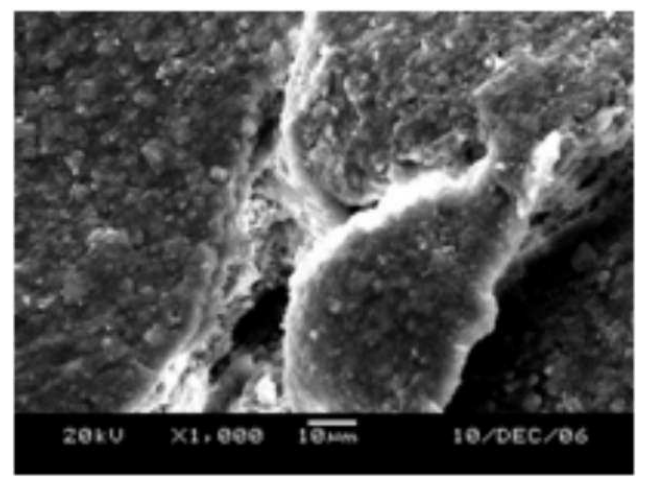

(f)

Fig. 9: SEM micrographs for virgin and the aged samples. (a): $\operatorname{SiR}($ New $) \times 1000$; (b): SiR (Aged) $\times 1000(\mathrm{UVA}=$ $1 \mathrm{~mW} \mathrm{~cm}{ }^{-2}$ ); (c): SiR (Aged) $\times 1000\left(\mathrm{UVA}=4 \mathrm{~mW} \mathrm{~cm}^{-2}\right)$; (d): TPE (New) $\times 1000$; (e): TPE (Aged) $\times 1000$ $\left(\right.$ UVA $\left.=1 \mathrm{~mW} \mathrm{~cm}^{-2}\right)$; (f): TPE (Aged) $\times 1000\left(\right.$ UVA $=4 \mathrm{~mW} \mathrm{~cm}^{-2}$ )

Fig. 10 shows the peak from the photo ionization of oxygen $\left(\mathrm{O}_{15}\right)$ and carbon $\left(\mathrm{C}_{15}\right)$ at 525 and $277 \mathrm{eV}$, respectively. It is also evident from these spectrums that $\%$ share of carbon and oxygen has rapidly increased from 17.97 and $34.06-20.13$ and $45.81 \%$ respectively in case of $\mathrm{SiR}$ and from 45.31 and 34.58 to 47.29 and $39.30 \%$, respectively in case of TPE, due to exposure to UVradiation and heat. The increase of $\mathrm{C}$ could be from the scission of $\mathrm{CH}_{3}$ bonds and the formation of various products due to reaction between $\mathrm{C}$ and $\mathrm{O}_{2}$ during oxidation.
In these samples, the presence of oxygen detected by XPS both in SiR and TPE on the new and aged surfaces is attributed to the availability of oxygen from the additives or from the moisture in the atmosphere or due to oxidation of the rubber during manufacturing ${ }^{[16]}$. Peaks of Al. are also observed in all samples as shown in Fig. 10. Slight traces of Ti were observed in case of TPE (new) as shown in Fig. 10a which disappeared due to aging where instead some traces of Vanadium were detected. This could be due to additives or any other decomposition process in the material during aging process. 
Am. J. Engg. \& Applied Sci., 2 (2):438-445, 2009

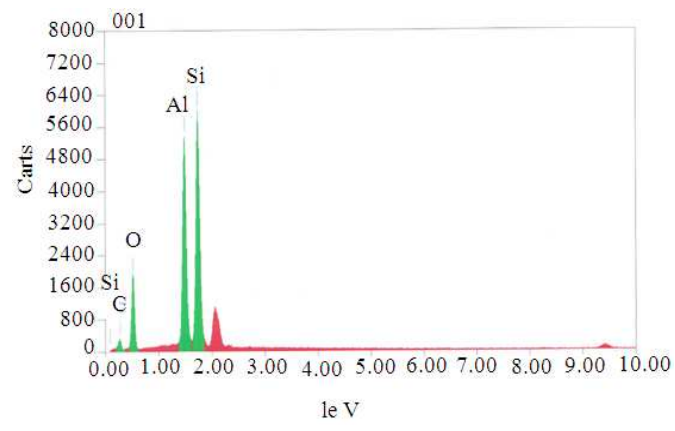

(a)

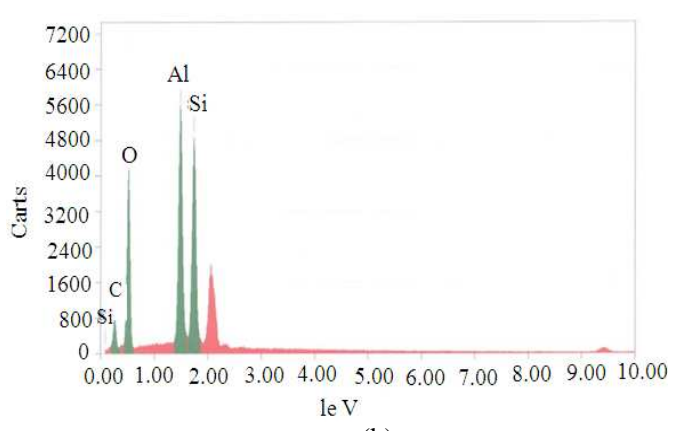

(b)

Fig. 10: XPS analysis of $\mathrm{SiR}$ (a): $\mathrm{SiR}$ insulator (New) (b): $\mathrm{SiR}$ insulator (Aged)

\begin{tabular}{lllll}
\multicolumn{6}{l}{ Table 5: Concentration (\%) of elements detected by XPS } \\
\hline $\begin{array}{l}\text { Elements } \\
(\mathrm{keV})\end{array}$ & SiR & & TPE & \\
\hline $\mathrm{C}(0.277)$ & New & Aged & New & Aged \\
$\mathrm{O}(0.525)$ & 17.97 & 20.13 & 45.31 & 47.29 \\
$\mathrm{Al}(1.486)$ & 34.06 & 45.81 & 34.58 & 39.30 \\
$\mathrm{Si}(1.739)$ & 21.69 & 17.95 & 17.29 & 13.08 \\
Others $(<5)$ & 26.28 & 16.11 & -- & -- \\
\hline
\end{tabular}

Table 5 shows the percentage atomic concentration of $\mathrm{C}, \mathrm{O}$ and other elements in all the tested samples. It can be seen that contents of $\mathrm{C}$ decreased after exposure while that of oxygen increased which indicate the formation of oxygenated species on the surface. The presence of oxygen in the aged samples could be easily attributed to the curing reaction between the material and other agents in the environment. The aged surfaces have different physical, chemical and electrical properties due to different chemical compounds at different binding energies (compared to new) because of weathering/ photo-oxidation, as observed from XPS results.

\section{DISCUSSION}

Since the oxygen exists in different forms of products, in the chemicals it is difficult to use the exact form of product to evaluate the degradation process. In this study, the components of oxygen and $\mathrm{C}$ on the tested surfaces were analyzed by XPS system. The ratio of $\mathrm{O}_{2} / \mathrm{C}$ was adopted to determine the order of degradation reaction. The dependence of $\mathrm{O}_{2} / \mathrm{C}$ ratio increased with increasing UV-A radiations intensity as compared to new samples as shown in Fig. 11. From the above discussion it is evident that sunlight (high intensity UV-A radiations) is an important factor in the degradation of polymers. This results from the breakage of certain C-C and $\mathrm{C}-\mathrm{H}$ bonds by the $\mathrm{UV}$ radiation. This is especially true for polymers containing dienemonomers, which are more susceptible to oxidation because of the presence of an alclyic group in the polymer backbone.

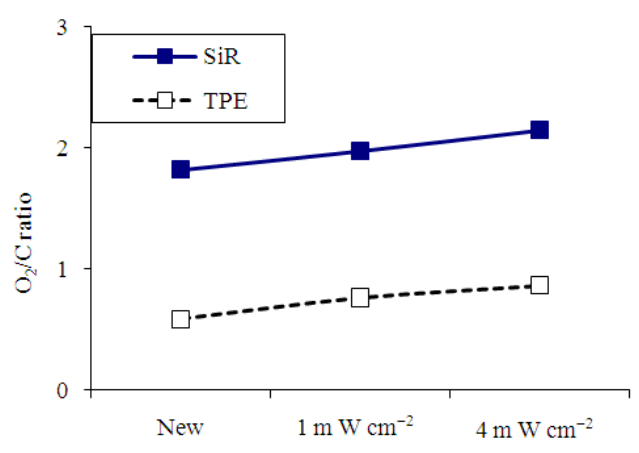

Fig. 11:Dependence of $\mathrm{O} / \mathrm{C}$ ratio on aging and UV radiation intensity

Mere sunlight is not enough for causing deterioration. Chromophoric groups are also necessary to absorb the incident radiation and transfer energy to the bond ${ }^{[17]}$. In polymers, chromophoric groups are present in the unsaturated structures, such as carbonyl groups which are formed during manufacturing.

The energy of a photon of light is transferred to the molecule with resultant bond scission. The resulting effects may include embrittlement, discoloration and cleavage of polymer chains. For this reason, polymers are filled with UV stabilizers and antioxidants.

Some of the main steps in this reaction are as follows:

- Heat or light:

$$
\begin{aligned}
& \mathrm{RH} \rightarrow \mathrm{R} .+\mathrm{H} . \\
& \text { R. }+\mathrm{O}_{2} \rightarrow \mathrm{ROO} . \\
& \mathrm{ROO} .+\mathrm{RH} \rightarrow \mathrm{ROOH}+\mathrm{R} . \\
& \mathrm{ROOH} \rightarrow \mathrm{RO} .+\mathrm{OH} . \\
& 2 \mathrm{ROOH} \rightarrow \text { RO. }+ \text { ROO. }+\mathrm{H}_{2} \mathrm{O}
\end{aligned}
$$


$\mathrm{RO} .+\mathrm{RH} \rightarrow \mathrm{ROH}+\mathrm{R}$.

$\mathrm{HO} .+\mathrm{RH} \rightarrow \mathrm{ROH}+\mathrm{R}$.

$2 \mathrm{ROO} \rightarrow$ product ketones, alcohols and so on.

Radicals are formed during initiation react with oxygen, leading to chain reactions. The decomposition of hydroperoxides by heat or UV light (reaction 4) causes formation of alkoxy and hydroxy radicals leading to chain branching as evident by XPS results.

The above results indicate that UVA radiations and heat are important factors in the degradation of polymers. This results from the breakage of certain molecular bonds by the UV radiation on polymers as these are more susceptible to oxidation ${ }^{[11-13,15,17]}$. The surface roughness will be a source of dust and pollution accumulation and hence can cause decline in the dielectric performance of the composite insulator in the long term operation in actual power system.

\section{CONCLUSION}

This study shows various results of the accelerated laboratory aged samples of the SiR and TPE composite insulators that were aged for $1000 \mathrm{~h}$ as per modified IEC protocol ${ }^{[8]}$. It truly reflects the prevalent weather conditions related to arid desert conditions. The obtained electrical and optical results are compared with respect to new insulators and lead to following conclusions:

- From the electrical tests results after the artificial accelerated aging, the dielectric response of TPE insulators under the tested thermo-electric cum UV-irradiations outperforms SiR insulators

- The SEM results indicates that surface roughness of the aged samples in case of $\mathrm{SiR}$ is more as compared to new insulator however, negligible surface roughness was observed in case of aged TPE insulator when exposed to UV radiation of $1 \mathrm{~mW} \mathrm{~cm}^{-2}$. Whereas, very visible surface degradation in both types of materials is observed, when exposed to UV-radiation of $4 \mathrm{~mW} \mathrm{~cm}^{-2}$.

\section{ACKNOWLEDGEMENT}

The researcher is highly indebted to the Research Center, College of Engineering, King Saud University, Riyadh for technical support and Saudi Arabian Basic Industries Corporation (SABIC) for financial support of this project (No. 18/426).

\section{REFERENCES}

1. Valstose, A.E. and E.M. Sherif, 1990. Experience from Insulators with Silicone Rubber sheds and shed coatings. IEEE. Trans. Power Delivery, 5: 2030-2038. DOI: 10.1109/61.103698

2. Hackam, R., 1999. Outdoor HV composite polymeric insulators. IEEE. Trans. DEI., 6: 557-585. DOI: $10.1109 / 94.798114$

3. Sundararajan, R., E. Sundrarajan, A. Mehmood and J. Graveset, 2006. Multistress accelerated aging of polymer housed surge arresters under simulated coastal Florida conditions. IEEE. Trans. DEI., 13: 211-227. DOI: 10.1109/TDEI.2006.1593419

4. EPRI, Technical Brief, 2003. Polymer insulator survey. EPRI Report \#1007769.

http://ieeexplore.ieee.org/iel5/10441/33136/015606 80.pdf

5. CIGRE 22-00 (WG 03), 2000. Worldwide service experience with composite insulators. Electra, 1911: 27-23.

6. AI-Hamoudi, I.Y., 2002. Saudi Arabian utility looks to silicone insulators to improve system reliability and lower maintenance costs. INMR., 13: 232-237.

7. Kuchler, A. and F. Hammer, 1992. Insulating system for HVDC power apparatus. IEEE Trans. Elect. Insulat., 27: 601-609. DOI: 10.1109/14.142725

8. International Electrotechnical Commission (IEC) Std. 61109, 1992. Composite insulators for A.C overhead lines with a nominal voltage $\geq 1000 \mathrm{~V}$. http://www.complianceonline.com/ecommerce/con trol/product/ $\sim$ product_id=826173

9. Schneider, H.M., W.W. Guidi, C.W. Nicholls, J.T. Burnhams and J.F. Hails, 1993. Accelerated Aging And Flashover Tests On $138 \mathrm{Kv}$ Nonceramic Line Post Insulators, IEEE Trans. on PD, 1, pp.325-336. DOI: $10.1109 / 61.180353$

10. International Electrotechnical Commission (IEC) Std. No. 60060-1, 1989. High voltage test techniques. http://www.iec.ch/cgibin/procgi.pl/www/iecwww.p?wwwlang=e\&www prog=TCpubs.p\&progdb=db1\&committee

11. Khan, Y., M.I. Qureshi, N.H. Malik and A.A. Al-Arainy, 2006. Performance of composite insulators in simulated environmental conditions related to central region of Saudi Arabia. Proceeding of the International Conference on Emerging Technologies, Nov. 13-14, IEEE Xplore Press, USA., pp: 373-384. DOI: 10.1109/ICET.2006.336028 
12. Gorur, R.S., G.G. Karady, A. Jagota, M. Shah and B.C. Furumasu, 1992. Comparison of RTV silicone rubber coatings under artificial contamination in a fog chamber. IEEE. Trans. PD., 7: 713-719. DOI: 10.1109/61.127072

13. Ramos, G.N., M.T.R. Campillo and K.A. Naito, 1993. Study on the characteristics of various conductive contaminants accumulated on $\mathrm{HV}$ insulators. IEEE. Trans. PD., 8: 1842-1850. DOI: $10.1109 / 61.248293$

14. IEC Standard No.60383, 1993-04. Tests on Ceramic/Glass insulators for overhead lines with voltages $\geq 1000$ V. www.iec.ch/cgibin/procgi.pl/www/iecwww.p?search=text\&searchf or=insulators $\& w w w p r o g=s e a 22 . p$
15. Fritz, J. and M.J. Owen, 1995. Hydrophobicity recovery of plasma treated SiR. J. Adhesion, 54: 33-45.

16. Hillborg, H. and U.W.H. Gedde, 1999. Hydrophobicity changes in SiR. IEEE. Trans. EI., 6: 703-717. DOI: 10.1109/94.798127

17. Sundarajan, R., E. Sundarajan, A. Mohammad and J. Grames, 2006. Multi-stress accelerated aging of polymer housed surge arresters under simulated coastal Florida conditions. IEEE. Trans. DEI., 13: 211-228. DOI:10.1109/TDEI.2006.1593419 